\title{
INTERRELATIONSHIP OF THE PRO-INFLAMMATORY MARKER HSCRP WITH DYSLIPIDEMIC CHANGES: A COMPARATIVE STUDY BETWEEN SUBCLINICAL AND OVERT HYPOTHYROIDISM
}

\author{
Suparna Roy11, Ushasi Banerjee², Anindya Dasgupta ${ }^{3}$ \\ ${ }^{1}$ Assistant Professor, Department of Biochemistry, Calcutta National Medical College, Kolkata. \\ ${ }^{2}$ Assistant Professor, Department of Biochemistry, Calcutta National Medical College, Kolkata. \\ 3 Professor and Head, Department of Biochemistry, Calcutta National Medical College, Kolkata.
}

\begin{tabular}{l}
\hline ABSTRACT \\
\hline CONTEXT \\
Sustained hypercholesterolemia with low-grade inflammation makes hypothyroid patients more prone for cardiovascular \\
disorders. Recently, these risks are also becoming evident in Subclinical Hypothyroidism (SH).
\end{tabular}

\section{AIMS, SETTINGS AND DESIGN}

We made an effort to evaluate the interaction of hsCRP with dyslipidemic changes and their contributions as cardiovascular risk factors in both Subclinical ( $\mathrm{SH}$ ) and Overt Hypothyroidism $(\mathrm{OH})$ patients in a hospital based, case control study consisting of $30 \mathrm{OH}$, $34 \mathrm{SH}$ and 34 properly matched control subjects within a span of one year.

\section{METHODS}

Changes on serum hsCRP, TSH and fT4 levels were assessed by ELISA. Total serum Cholesterol (TC), LDL Cholesterol (LDLc), HDL Cholesterol (HDLc) and triglyceride (TG) were measured by standard pre-validated photometric tests as applicable.

\section{STATISTICAL ANALYSIS}

Data obtained were compared for difference between mean values by one way and post hoc ANOVA. Predictive values of individual lipid parameters on the rise of hsCRP were evaluated in both $\mathrm{OH}$ and $\mathrm{SH}$ groups by multivariate linear regression analysis. SPSS software, version 17 for Windows was used for all statistical analyses. For all analyses, $\mathrm{P}$ value was considered significant at a level of $\mathrm{P}<0.05$ for $95 \%$ confidence interval.

\section{RESULTS}

Post hoc ANOVA showed that mean values of hsCRP, TG, TC and LDLc were increased most in the OH group followed by that in the SH with a significant difference between two groups $(\mathrm{p}<0.001)$. In contrast, fT4 and HDLc showed decreased levels in both SH and $\mathrm{OH}$ groups, also with a significant difference between themselves. Results of multiple linear regression analysis revealed that $\operatorname{LDLc}(\beta=0.653, \mathrm{P}<0.001$ for SH and $\beta=0.326, \mathrm{P}=0.030$ for $\mathrm{OH})$ and $\mathrm{fT} 4(\beta=-0.241, \mathrm{P}=0.044$ for SH and $\beta=-0.444, \mathrm{P}=0.046$ for $\mathrm{OH})$ were most important positive and negative predictors respectively for changes in the hsCRP levels.

\section{CONCLUSIONS}

A low-grade inflammation starts in early stages of hypothyroidism, which is directly dependent on serum thyroxine and inversely dependent on LDLc. We conclude that there is a possible link between the development of low-grade inflammation and LDLc in the $\mathrm{SH}$ state that is more potentiated as the disease progresses to $\mathrm{OH}$.

\section{KEYWORDS}

High Sensitive C Reactive Protein; Hypercholesterolemia; LDL Cholesterol; Overt Hypothyroidism; Pro-Inflammatory State; Subclinical Hypothyroidism.

HOW TO CITE THIS ARTICLE: Roy S, Banerjee U, Dasgupta A. Interrelationship of the pro-inflammatory marker HSCRP with dyslipidemic changes: a comparative study between subclinical and overt hypothyroidism. J. Evolution Med. Dent. Sci. 2016;5(16): 806-812, DOI: $10.14260 /$ jemds/2016/186

\section{INTRODUCTION}

Hypothyroidism is one of the commonest endocrine disorders throughout the world with a prevalence of $2-15 \%$ in USA and Europe.[1] In India it is reported to be the second commonest endocrine disorder after diabetes mellitus.[2] Primary hypothyroidism is manifested as either Overt Hypothyroidism $(\mathrm{OH})$ or Subclinical Hypothyroidism (SH).

Financial or Other, Competing Interest: None.

Submission 10-01-2016, Peer Review 07-02-2016,

Acceptance 12-02-2016, Published 25-02-2016.

Corresponding Author:

Dr. Anindya Dasgupta,

Professor and HOD, Department of Biochemistry,

Calcutta National Medical College,

Kolkata-14.

E-mail: anindya653@gmail.com

DOI: $10.14260 /$ jemds/2016/186
$\mathrm{OH}$ is defined as an elevated serum TSH with decreased thyroxine level, whereas $\mathrm{SH}$ the milder spectrum of the disease is defined as elevated serum TSH with blood thyroxine within the normal reference interval. $\mathrm{SH}$, sometimes known as the compensated hypothyroidism also has a substantial prevalence of 4-10.[3] percent among general population and about 7-10 percent among the elderly.[4] The clinical importance of SH is revealed by an explicit association of this disease with poor left ventricular function and increased arterial stiffness.[5,6] Furthermore, the Rotterdam study has provided significant evidence of arterial atherosclerosis and myocardial infarction in elderly women with SH.

Deranged blood lipid profile is a characteristic feature in established hypothyroidism. Regarding changes in lipid profile in $\mathrm{SH}$, variable results have been reported with conflicting reports involving both normal.[7] and elevated levels.[8,9] for 
LDL cholesterol fraction (LDLC). Furthermore, the significant increase in its levels has been reported to be normalized in $\mathrm{SH}$ patients after thyroxine therapy.[9] Indicating a direct link between the LDLc metabolism and circulating levels of thyroxine. Results in Norway and Australia reported significant association between lipid profile with SH, whereas the Suita study did not find any such observations.[10] Recent studies including some based on a large sample size of 60000 patients have also indicated a significantly elevated levels of TC and LDLc in the SH patients compared to the control subjects. Some of the studies also found substantial decrease in the TG level after replacement therapy with thyroxine in SH patients.[11]

All these observations suggest that in spite of inconsistent results, SH patients may be in a state of mild thyroid failure and hence are more liable to suffer from atherosclerotic and cardiovascular diseases than the normal population.[12,13] However, due to inconsistency in these observations in different studies undertaken in different geographical regions, further investigation are needed to reach a more conclusive opinion and a comprehensive understanding of the interplay of metabolic events in SH for a better understanding of its clinical outcome.

In addition to a sustained hyperlipidemia, the prevalence of a state of low-grade inflammation potentiates the cardiovascular risks for hypothyroid patients. Till date, variable results are available regarding changes in the hsCRP levels in the $\mathrm{SH}$ patients. Some studies have reported significant rise in this marker of low-grade inflammation in the SH group.[14,15] while other did not find any such change.[16] However, recent studies have not only described a raised hsCRP level in SH patients compared to healthy controls.[17] but also reported its normalization after appropriate replacement therapy with thyroxine.[18,19] Furthermore, a link between hyperlipidemia and changes in hsCRP has been cued in hypothyroid cases that has not been yet explored much in the SH group.

Keeping these factors in mind and the potential risk of simultaneous increase in hsCRP and atherogenic lipids for cardiovascular disorders, we hypothesized that the low-grade inflammatory marker hsCRP might be elevated in SH as well as in the $\mathrm{OH}$ patients and this increase might be dependent on the circulating thyroxine levels along with some particular lipid fraction like TG, LDL or HDL. Accordingly, the present study was designed to test this hypothesis.

\section{MATERIAL AND METHODS}

\section{Study Design and Settings}

The present study was conducted in the Department of Biochemistry of a Tertiary Care Medical College and Hospital, West Bengal, India. It was a case control non-interventional study that spanned a period of one year from February 2013 to January 2014.

\section{Selection of Cases and Controls}

Sixty four cases aged between 20 to 40 years were selected on convenience basis from the thyroid clinic of the Biochemistry Department during the stipulated study period.

\section{Inclusion Criteria}

We planned to segregate the case group into $\mathrm{OH}$ and $\mathrm{SH}$ based on the result of serum fT4 level as follows: i) SH group with raised TSH, but fT4 within reference range (0.8-2.0ng/dL) and ii) $\mathrm{OH}$ group with raised TSH and fT4 below the reference range $(<0.8 \mathrm{ng} / \mathrm{dL})$. Cases were selected between the age group of $20-40$ yrs by the method of convenience with no male-female discretion. 34 healthy control subjects matched for age and sex were selected from the same population group belonging to similar socioeconomic and nutritional status.

\section{Exclusion Criteria}

Patients having history of chronic alcohol ingestion, smoking, drug addiction, any malignant disorder, chronic inflammatory diseases and any other metabolic or endocrinological disorders were excluded. Same exclusion criteria were followed for selection of the control subjects.

\section{Ethical Guidelines}

Informed consents were obtained from both the cases and control groups as per protocol. Institutional ethical clearance was obtained before start of the study. Total study adhered to the guidelines of the ICMR's Ethical guidelines for biomedical research on human participants, (2006) and the Helsinki Declaration 1975, revised in 2000.

\section{METHODOLOGY}

1. Serum TSH and fT4 were estimated by competitive and non-competitive ELISA respectively by the reagent kits obtained from AccuBind, USA. The coefficient of variation $(\mathrm{CV})$ were found to be 6 percent and 8 percent for the TSH and fT4 respectively.

2. Serum hsCRP was measured by immunoturbidimetric method obtained from ERBA, Transasia. CV for this assay was 5 percent for this assay.

3. Serum lipids were estimated by standard photometric techniques with the autoanalyzer, XL 600 from ERBA, Transasia. Cholesterol was estimated by the CHOD-PAP method, whereas the LDLc and HDLc were measured by direct methods. All reagents were obtained from ERBA, Transasia. The CV for these assays remained within 6 percent throughout the assay process.

\section{Statistical Analysis}

Data were analysed for the significance of difference between the mean values by post hoc ANOVA between the $\mathrm{OH}, \mathrm{SH}$ and control groups. Dependence and predictive values of the study parameters in the case group were analysed with the help of multiple linear regression study. For all studies, the $P$ value was considered to be significant at a level of 0.05 or less with a confidence interval of $95 \%$. All relevant statistical analysis were performed by using SPSS software for Windows, version 17.

\section{RESULTS}

Difference between the mean values of study parameters: The Table 1 shows the results of one way ANOVA performed on $\mathrm{OH}, \mathrm{SH}$ and normal control subjects. From the p values ( $p<0.001$ for all parameters), it is evident that the overall difference between these three groups was significant. However, to ascertain the degree of difference between the individual of $\mathrm{OH}, \mathrm{SH}$ and control groups post hoc ANOVA with Bonferroni correction was performed and the results are shown in the Table 2. 
In Table 2, the post hoc ANOVA revealed the significance of difference between the individual groups separately while Bonferroni correction compensated for the multiple comparisons. Mean values of serum TSH, TG, TC, LDLc and hsCRP showed significant increase $(p<0.001)$ in the $\mathrm{OH}$ groups compared to $\mathrm{SH}$ groups, that in turn showed a significant higher values than the control subjects $(\mathrm{p}<0.001)$. On the other hand, values of fT4 and HDLc showed significant trend in opposite direction showing marked reduction in their values ( $\mathrm{p}<0.001)$, most in the $\mathrm{OH}$ group followed by that in the $\mathrm{SH}$ and the normal controls.

Results for age and BMI matching are shown in Table 3. In table III post hoc ANOVA revealed that there was no significant difference between the age and BMI distribution indicating that all three groups were matched for age and body weight. Chi square test indicated that these three groups were also sex matched $(\chi 2=0.09, p=0.95$, data not shown in Table).
The degree of dependence of hsCRP on the thyroid parameters and the lipid profile in the SH groups is shown in the Table 4. FT4 value showed a strong negative predictive effect on the hsCRP with the TSH exhibiting an opposite effect. Similarly, the predictive value of LDL is found to be significantly positive on the increase of the hsCRP. No such effects from the HDLc and TG were observed.

Table 5 shows the degree of dependence of hsCRP on thyroid parameters and lipid profile in the $\mathrm{OH}$ group. Among the thyroid parameters, fT4 value is found to have a strong negative predictive value on the hsCRP without any such effect from the TSH. The predictive value of LDLc is found to be significantly positive on the increase on hsCRP. No such effects from the HDLc and TG were observed on hsCRP.

\begin{tabular}{|c|c|c|c|c|c|c|}
\hline & & Sum of Squares & df & $\begin{array}{c}\text { Mean } \\
\text { Square } \\
\end{array}$ & $\mathbf{F}$ & Sig. (P value) \\
\hline \multirow{3}{*}{$\begin{array}{c}\text { TSH } \\
(\mu \mathrm{IU} / \mathrm{mL})\end{array}$} & Between Groups & 7694.824 & 2 & 3847.412 & 131.547 & $. P<0.001$ \\
\hline & Within Groups & 2807.744 & 96 & 29.247 & & \\
\hline & Total & 10502.568 & 98 & & & \\
\hline \multirow{3}{*}{$\begin{array}{c}\mathrm{fT} 4 \\
(\mathrm{ng} / \mathrm{dL})\end{array}$} & Between Groups & 19.414 & 2 & 9.707 & 130.448 & $\mathrm{P}<0.001$ \\
\hline & Within Groups & 7.144 & 96 & .074 & & \\
\hline & Total & 26.558 & 98 & & & \\
\hline \multirow{3}{*}{$\begin{array}{l}\text { HSCRP } \\
(\mathrm{mg} / \mathrm{L})\end{array}$} & Between Groups & 464.152 & 2 & 232.076 & 49.008 & $\mathrm{P}<0.001$ \\
\hline & Within Groups & 454.608 & 96 & 4.736 & & \\
\hline & Total & 918.761 & 98 & & & \\
\hline \multirow{3}{*}{$\mathrm{TC}(\mathrm{mg} / \mathrm{dL})$} & Between Groups & 67950.815 & 2 & 33975.408 & 45.723 & $\mathrm{P}<0.001$ \\
\hline & Within Groups & 71334.356 & 96 & 743.066 & & \\
\hline & Total & 139285.172 & 98 & & & \\
\hline \multirow{3}{*}{$\begin{array}{c}\mathrm{TG} \\
(\mathrm{mg} / \mathrm{dL})\end{array}$} & Between Groups & 175966.174 & 2 & 87983.087 & 66.194 & $\mathrm{P}<0.001$ \\
\hline & Within Groups & 127599.482 & 96 & 1329.161 & & \\
\hline & Total & 303565.657 & 98 & & & \\
\hline \multirow{3}{*}{$\begin{array}{c}\mathrm{LDL} \\
(\mathrm{mg} / \mathrm{dL})\end{array}$} & Between Groups & 44399.149 & 2 & 22199.574 & 34.692 & $\mathrm{P}<0.001$ \\
\hline & Within Groups & 61430.597 & 96 & 639.902 & & \\
\hline & Total & 105829.745 & 98 & & & \\
\hline \multirow{3}{*}{$\begin{array}{c}\text { HDL } \\
(\mathrm{mg} / \mathrm{dL})\end{array}$} & Between Groups & 1910.975 & 2 & 955.488 & 17.758 & $\mathrm{P}<0.001$ \\
\hline & Within Groups & 5165.252 & 96 & 53.805 & & \\
\hline & Total & 7076.227 & 98 & & & \\
\hline
\end{tabular}

${ }^{*} \mathrm{P}$ value is considered significant at $\mathrm{P}<0.05$ for $95 \%$ confidence interval. 


\begin{tabular}{|c|c|c|c|c|c|}
\hline Dependent Variable & $\begin{array}{c}\text { (I) } \\
\text { VAR00009 }\end{array}$ & $\begin{array}{c}\text { (J) } \\
\text { VAR00009 }\end{array}$ & $\begin{array}{c}\text { Mean Difference } \\
\text { (I-J) }\end{array}$ & Std. Error & Sig. \\
\hline \multirow{6}{*}{$\begin{array}{c}\mathrm{TSH} \\
(\mu \mathrm{IU} / \mathrm{mL})\end{array}$} & \multirow{2}{*}{1.00} & 2.00 & $9.38339^{*}$ & 1.35467 & $\mathrm{P}<0.001$ \\
\hline & & 3.00 & $21.66019^{*}$ & 1.34557 & $\mathrm{P}<0.001$ \\
\hline & \multirow{2}{*}{2.00} & 1.00 & $-9.38339^{*}$ & 1.35467 & $P<0.001$ \\
\hline & & 3.00 & $12.27680^{*}$ & 1.30225 & $\mathrm{P}<0.001$ \\
\hline & \multirow{2}{*}{3.00} & 1.00 & $-21.66019^{*}$ & 1.34557 & $\mathrm{P}<0.001$ \\
\hline & & 2.00 & $-12.27680^{*}$ & 1.30225 & $\mathrm{P}<0.001$ \\
\hline \multirow{6}{*}{$\begin{array}{c}\mathrm{fT} 4 \\
\text { (ng/dL) }\end{array}$} & \multirow{2}{*}{1.00} & 2.00 & $-.82378^{*}$ & .06833 & $\mathrm{P}<0.001$ \\
\hline & & 3.00 & $-1.05410^{*}$ & .06787 & $P<0.001$ \\
\hline & \multirow{2}{*}{2.00} & 1.00 & $.82378^{*}$ & .06833 & $\mathrm{P}<0.001$ \\
\hline & & 3.00 & $-.23031^{*}$ & .06569 & $\mathrm{P}<0.001$ \\
\hline & \multirow{2}{*}{3.00} & 1.00 & $1.05410^{*}$ & .06787 & $\mathrm{P}<0.001$ \\
\hline & & 2.00 & $.23031^{*}$ & .06569 & $\mathrm{P}<0.001$ \\
\hline \multirow{6}{*}{$\begin{array}{l}\text { HSCRP } \\
(\mathrm{mg} / \mathrm{L})\end{array}$} & \multirow{2}{*}{1.00} & 2.00 & $1.87451^{*}$ & .54510 & $P<0.001$ \\
\hline & & 3.00 & $5.24305^{*}$ & .54143 & $\mathrm{P}<0.001$ \\
\hline & \multirow{2}{*}{2.00} & 1.00 & $-1.87451^{*}$ & .54510 & $P<0.001$ \\
\hline & & 3.00 & $3.36854^{*}$ & .52400 & $\mathrm{P}<0.001$ \\
\hline & \multirow{2}{*}{3.00} & 1.00 & $-5.24305^{*}$ & .54143 & $\mathrm{P}<0.001$ \\
\hline & & 2.00 & $-3.36854^{*}$ & .52400 & $\mathrm{P}<0.001$ \\
\hline \multirow{6}{*}{$\begin{array}{c}\mathrm{TC} \\
(\mathrm{mg} / \mathrm{dL})\end{array}$} & \multirow{2}{*}{1.00} & 2.00 & $35.07059^{*}$ & 6.82816 & $\mathrm{P}<0.001$ \\
\hline & & 3.00 & $64.85714^{*}$ & 6.78228 & $\mathrm{P}<0.001$ \\
\hline & \multirow{2}{*}{2.00} & 1.00 & $-35.07059^{*}$ & 6.82816 & $P<0.001$ \\
\hline & & 3.00 & $29.78655^{*}$ & 6.56394 & $P<0.001$ \\
\hline & \multirow{2}{*}{3.00} & 1.00 & $-64.85714^{*}$ & 6.78228 & $\mathrm{P}<0.001$ \\
\hline & & 2.00 & $-29.78655^{*}$ & 6.56394 & $\mathrm{P}<0.001$ \\
\hline \multirow{6}{*}{$\begin{array}{c}\mathrm{TG} \\
(\mathrm{mg} / \mathrm{dL})\end{array}$} & \multirow{2}{*}{1.00} & 2.00 & $42.94118^{*}$ & 9.13227 & $\mathrm{P}<0.001$ \\
\hline & & 3.00 & $103.30000^{*}$ & 9.07091 & $\mathrm{P}<0.001$ \\
\hline & \multirow{2}{*}{2.00} & 1.00 & $-42.94118^{*}$ & 9.13227 & $\mathrm{P}<0.001$ \\
\hline & & 3.00 & $60.35882^{*}$ & 8.77890 & $\mathrm{P}<0.001$ \\
\hline & \multirow{2}{*}{3.00} & 1.00 & $-103.30000^{*}$ & 9.07091 & $\mathrm{P}<0.001$ \\
\hline & & 2.00 & $-60.35882^{*}$ & 8.77890 & $\mathrm{P}<0.001$ \\
\hline \multirow{6}{*}{$\begin{array}{c}\mathrm{LDL} \\
(\mathrm{mg} / \mathrm{dL})\end{array}$} & \multirow{2}{*}{1.00} & 2.00 & $26.93922^{*}$ & 6.33646 & $\mathrm{P}<0.001$ \\
\hline & & 3.00 & $52.40476^{*}$ & 6.29388 & $\mathrm{P}<0.001$ \\
\hline & \multirow{2}{*}{2.00} & 1.00 & $-26.93922^{*}$ & 6.33646 & $P<0.001$ \\
\hline & & 3.00 & $25.46555^{*}$ & 6.09127 & $\mathrm{P}<0.001$ \\
\hline & \multirow{2}{*}{3.00} & 1.00 & $-52.40476^{*}$ & 6.29388 & $\mathrm{P}<0.001$ \\
\hline & & 2.00 & $-25.46555^{*}$ & 6.09127 & $\mathrm{P}<0.001$ \\
\hline \multirow{6}{*}{$\begin{array}{c}\mathrm{HDL} \\
(\mathrm{mg} / \mathrm{dL})\end{array}$} & & 2.00 & $-4.58137^{*}$ & 1.83738 & $\mathrm{P}=0.043$ \\
\hline & 1.00 & 3.00 & $-10.78095^{*}$ & 1.82504 & $\mathrm{P}<0.001$ \\
\hline & & 1.00 & $4.58137^{*}$ & 1.83738 & $\mathrm{P}=0.043$ \\
\hline & 2.00 & 3.00 & $-6.19958^{*}$ & 1.76629 & $P=0.002$ \\
\hline & 300 & 1.00 & $10.78095^{*}$ & 1.82504 & $\mathrm{P}<0.001$ \\
\hline & 3.00 & 2.00 & $6.19958^{*}$ & 1.76629 & $P=0.002$ \\
\hline
\end{tabular}

Table 2: Multiple Comparisons between the biochemical parameters using post hoc ANOVA with Bonferroni correction

*P value is considered significant at $\mathrm{P}<0.05$ for $95 \%$ confidence interval.

\begin{tabular}{|c|c|c|c|c|c|}
\hline $\begin{array}{c}\text { Dependent } \\
\text { Variable }\end{array}$ & $\begin{array}{c}\text { (I) } \\
\text { VAR00010 }\end{array}$ & $\begin{array}{c}\text { (J) } \\
\text { VAR00010 }\end{array}$ & $\begin{array}{c}\text { Mean } \\
\text { Difference (I-J) }\end{array}$ & $\begin{array}{l}\text { Std. } \\
\text { Error }\end{array}$ & Sig. \\
\hline \multirow{6}{*}{ BMI } & \multirow{2}{*}{1.00} & 2.00 & -.45686 & .54070 & $\mathrm{P}=1.000$ \\
\hline & & 3.00 & -.53333 & .53707 & $\mathrm{P}=0.970$ \\
\hline & \multirow{2}{*}{2.00} & 1.00 & .45686 & .54070 & $\mathrm{P}=1.000$ \\
\hline & & 3.00 & -.07647 & .51978 & $\mathrm{P}=1.000$ \\
\hline & \multirow{2}{*}{3.00} & 1.00 & .53333 & .53707 & $\mathrm{P}=0.970$ \\
\hline & & 2.00 & .07647 & .51978 & $\mathrm{P}=1.000$ \\
\hline \multirow{6}{*}{$\begin{array}{c}\text { AGE } \\
\text { (Years) }\end{array}$} & \multirow{2}{*}{1.00} & 2.00 & -1.74118 & 1.63612 & $\mathrm{P}=0.870$ \\
\hline & & 3.00 & 1.22857 & 1.62513 & $\mathrm{P}=1.000$ \\
\hline & \multirow{2}{*}{2.00} & 1.00 & 1.74118 & 1.63612 & $\mathrm{P}=0.870$ \\
\hline & & 3.00 & 2.96975 & 1.57281 & $\mathrm{P}=0.186$ \\
\hline & \multirow{2}{*}{3.00} & 1.00 & -1.22857 & 1.62513 & $\mathrm{P}=1.000$ \\
\hline & & 2.00 & -2.96975 & 1.57281 & $\mathrm{P}=0.186$ \\
\hline & Table 3: & $\begin{array}{l}\text { le Compar } \\
\text { g post hoc }\end{array}$ & $\begin{array}{l}\text { s between the a } \\
\text { OVA with Bonfe }\end{array}$ & $\begin{array}{l}\text { ometric p } \\
\text { orrection }\end{array}$ & \\
\hline
\end{tabular}

${ }^{*} \mathrm{P}$ value is considered significant at $\mathrm{P}<0.05$ for $95 \%$ confidence interval. 


\begin{tabular}{|c|c|c|c|c|c|c|}
\hline \multicolumn{7}{|c|}{ Coefficients $^{a}$} \\
\hline & \multirow[t]{2}{*}{ Model } & \multicolumn{2}{|c|}{ Unstandardized Coefficients } & \multirow{2}{*}{$\begin{array}{c}\begin{array}{c}\text { Standardized } \\
\text { Coefficients }\end{array} \\
\text { Beta }\end{array}$} & \multirow[t]{2}{*}{$\mathbf{t}$} & \multirow[t]{2}{*}{ Sig. } \\
\hline & & B & Std. Error & & & \\
\hline \multirow{6}{*}{1} & (Constant) & -6.904 & 5.141 & & -1.343 & $\mathrm{P}=0.190$ \\
\hline & TSH & 0.179 & 0.072 & 0.245 & 2.494 & $P=0.019$ \\
\hline & FT4 & -3.110 & 1.473 & -0.241 & -2.111 & $P=0.044$ \\
\hline & TG & 0.000 & 0.009 & -0.003 & -0.031 & $\mathrm{P}=0.975$ \\
\hline & LDL & 0.129 & 0.017 & 0.653 & 7.520 & $\mathrm{P}<0.001$ \\
\hline & HDL & 0.007 & 0.048 & 0.014 & 0.145 & $P=0.885$ \\
\hline
\end{tabular}

Table 4: Multiple linear regression showing the dependence of hSCRP on the thyroid and lipid parameters in SH patients

${ }^{*} \mathrm{P}$ value is considered significant at $\mathrm{P}<0.05$ for $95 \%$ confidence interval.

\begin{tabular}{|c|c|c|c|c|c|c|}
\hline \multicolumn{7}{|c|}{ Coefficients $^{\mathbf{a}}$} \\
\hline & \multirow[t]{2}{*}{ Model } & \multicolumn{2}{|c|}{$\begin{array}{c}\text { Unstandardized } \\
\text { Coefficients }\end{array}$} & \multirow{2}{*}{$\begin{array}{c}\begin{array}{c}\text { Standardized } \\
\text { Coefficients }\end{array} \\
\text { Beta } \\
\end{array}$} & \multirow[t]{2}{*}{ t } & \multirow[t]{2}{*}{ Sig. } \\
\hline & & B & Std. Error & & & \\
\hline \multirow{6}{*}{1} & (Constant) & 4.166 & 6.470 & & 0.644 & $P=0.526$ \\
\hline & TSH & 0.058 & 0.109 & 0.111 & 0.534 & $P=0.598$ \\
\hline & fT4 & -9.393 & 4.456 & -0.444 & -2.108 & $P=0.046$ \\
\hline & $\mathrm{TG}$ & 0.013 & 0.018 & 0.115 & 0.754 & $\mathrm{P}=0.458$ \\
\hline & LDL & 0.053 & 0.023 & 0.326 & 2.314 & $\mathrm{P}=0.030$ \\
\hline & HDL & -0.025 & 0.058 & -0.036 & -0.437 & $\mathrm{P}=0.666$ \\
\hline \multicolumn{7}{|c|}{ a. Dependent Variable: hsCRP $(\mathrm{OH})$} \\
\hline
\end{tabular}

$* \mathrm{P}$ value is considered significant at $\mathrm{P}<0.05$ for $95 \%$ confidence interval.

\section{DISCUSSION}

In the present study, although we observed significant elevations in TSH in both $\mathrm{OH}$ and $\mathrm{SH}$ groups compared to the control subjects, the increase was more in the OH group than found in the SH patients. Similar trends were observed for TC, LDL and TG levels while an opposite change was found for fT4 and HDL among these groups (Post hoc ANOVA, table II). These observations indicated clearly that along with $\mathrm{OH}, \mathrm{SH}$ patients showed altered biochemical parameters albeit lower than found in their $\mathrm{OH}$ counterparts. However, as these changes in the SH group were significantly higher than that found in the normal control subjects, these patients are supposed to face significant consequences of altered metabolic status due to a mild thyroid failure characteristic of the SH.

Elevated atherogenic lipids, i.e. TC, LDL and TG along with a reduced cardioprotective lipoprotein HDL level render SH patients more prone to serious complications like premature atherosclerotic incidences and cardiovascular attacks compared to the normal population. Our findings and interpretations keep in track with the earlier as well as the recent observations that a mild thyroid failure does occur in SH state and that is sufficient to pose significant atherosclerotic and cardiovascular threat in these patients. ${ }^{[12,17]}$ although, some degree of variable association of lipid profile with SH has been attributed to differences in genetic background and body weight distribution among individuals. ${ }^{[10]}$ These factors are not supposed to play critical role in our study group as the $\mathrm{OH}, \mathrm{SH}$ and control groups were all matched for their age and body weights.

However, we did not study any genetic profile in these patients in the present study and keep it for further research. Although several studies have reported changes in apolipoproteins in hypothyroid patients, conventional lipid risk factors and CRP have been reported to be better markers for cardiovascular risks.[20] In hypothyroidism, several lowgrade immunological markers have been found to be increased that include hsCRP.[21] anti-TPO, anti-TG antibodies, etc. This low-grade inflammation has been found to play a significant role in sympathovagal imbalance that is one of the major contributing factors leading to cardiovascular abnormalities. Sympathovagal imbalance has been found to be one of the major contributing factors for increases in lipid parameters like TC, TG and LDLc in hypothyroid disorders. ${ }^{[22]}$

In $\mathrm{SH}$, studies have reported changes in TC and LDL levels to be so significant that they remained unaltered even after correction for the age and gender.[13,23] In our study, the multiple linear regression analysis (Table IV and V) also revealed LDLc to be the most important predictor for the rise in hsCRP level in both $\mathrm{SH}$ and $\mathrm{OH}$ groups. Increases in lowgrade inflammatory markers have been already reported in previous studies like elevation in hsCRP and CD40 ligands in SH.[18] But in addition to the dyslipidemic changes and increased hsCRP levels found in hypothyroid patients, the findings of our study further suggests that the rise in hsCRP levels is dependent on the extent of increase in LDLc in blood that renders these patients more vulnerable to the cardiovascular risks from the combined effects of dyslipidemia and a low-grade inflammatory state.

In our study, hsCRP levels were found to be dependent on both TSH and fT4 in SH groups, while on only fT4 in the OH group (Table IV and V). Changes in the hsCRP levels were reported to be associated with serum TSH in a graded manner in SH patients in some previous studies.[24] These observations along with the findings in our study clearly indicate that serum TSH levels have a significant predictive role on hsCRP in $\mathrm{SH}$ patients. As a compensatory increase in serum TSH in $\mathrm{SH}$ makes an effort to maintain the compromised thyroxine levels within normal reference range, elevated levels of TSH in blood 
are sustained to maintain the normal thyroxine levels in serum. However, as the patients progress to $\mathrm{OH}$, the compensatory mechanism of TSH elevation is subdued and serum levels of thyroxine starts falling down. This partially explains the observation in our study that although, hsCRP is dependent on both fT4 and TSH in SH patients, it is dependent only on fT 4 in $\mathrm{OH}$ cases.

In conclusion, findings of the present study indicate that a pro-inflammatory or a low-grade inflammatory state prevails even in the early stages of mild thyroid failure, i.e. the SH state and furthermore this elevation shows a graded response along with the decrease in thyroxine level and increase in blood LDLc fraction through the course of the disease. Although, some studies have negated the need of replacement therapy at the SH stage, others have advocated that therapy with thyroxine has been found to provide significant improvement of these biochemical parameters in $\mathrm{SH}$ patients that has been found to cause significant improvement in carotid arterial intimal thickness. ${ }^{[4]}$ subclinical inflammation.[25] and hemostatic defects.[26] Keeping these factors in mind and the significant dependence of the hsCRP on fT4 and LDLc in a graded manner we suggest identification of $\mathrm{SH}$ at an earliest possible stage followed by appropriate replacement therapy as needed.

However, our observations and interpretations need to be judged in the context of inherent limitations of the case control non-interventional studies, limited sample size and lack of genetic evidences that may affect the population variation. In addition to above conclusions we thus propose the need for further research considering larger sample sizes in different cohorts involving both biochemical and genetic factors.

\section{REFERENCES}

1. Vanderpump MP. The epidemiology of thyroid disease. Br Med Bull 2011;99:39-51.

2. Delange F, de Benoist B, Burgi H. Determining median urinary iodine concentration that indicates adequate iodine intake at population level. Bull World Health Organ 2002;80:633-6.

3. Canaris GJ, Manowitz NR, Mayor G, et al. The Colorado thyroid disease prevalence study. Arch Intern Med 2000;160:526-34.

4. Hak AE, Pols HA, Visser TJ, et al. Subclinical hypothyroidism is an independent risk factor for atherosclerosis and myocardial infarction in elderly women: the Rotterdam Study. Ann Intern Med 2000;132:270-8.

5. Dagre AG, Lekakis JP, Papaioannou TG, et al. Arterial stiffness is increased in subjects with hypothyroidism. Int J Cardiol 2005;103:1-6.

6. Biondi B, Klein I. Hypothyroidism as a risk factor for cardiovascular disease. Endocrine 2004;24:1-13.

7. Hueston WJ, Pearson WS. Subclinical hypothyroidism and the risk of hypercholesterolemia. Ann Fam Med 2004;2:351-5.

8. Walsh JP, Bremner AP, Bulsara MK, et al. Thyroid dysfunction and serum lipids: a community-based study. Clin Endocrinol (Oxf) 2005;63:670-5.
9. Iqbal A, Jorde R, Figenschau Y. Serum lipid levels in relation to serum thyroid-stimulating hormone and the effect of thyroxine treatment on serum lipid levels in subjects with subclinical hypothyroidism: the Tromso Study. J Intern Med 2006;260:53-61.

10. Takashima N, Niwa Y, Mannami T, et al. Characterization of subclinical thyroid dysfunction from cardiovascular and metabolic viewpoints: the Suita study. Circ J 2007;71:191-5.

11. Lee MW, Shin DY, Kim KJ, et al. The biochemical prognostic factors of subclinical hypothyroidism. Endocrinol Metab (Seoul) 2014;29:154-62.

12. Tanis BC, Westendorp GJ, Smelt HM. Effect of thyroid substitution on hypercholesterolaemia in patients with subclinical hypothyroidism: a reanalysis of intervention studies. Clin Endocrinol (Oxf) 1996;44:643-9.

13. Jung CH, Sung KC, Shin HS, et al. Thyroid dysfunction and their relation to cardiovascular risk factors such as lipid profile, hsCRP and waist hip ratio in Korea. Korean J Intern Med 2003;18:146-53.

14. Sharma R, Sharma TK, Kaushik GG, et al. Subclinical hypothyroidism and its association with cardiovascular risk factors. Clin Lab 2011;57:719-24.

15. Tuzcu A, Bahceci M, Gokalp D, et al. Subclinical hypothyroidism may be associated with elevated highsensitive C-reactive protein (low-grade inflammation) and fasting hyperinsulinemia. Endocr J 2005;52:89-94.

16. Toruner F, Altinova AE, Karakoc A, et al. Risk factors for cardiovascular disease in patients with subclinical hypothyroidism. Adv Ther 2008;25:430-7.

17. Roy S, Banerjee U, Dasgupta A. Effect of subclinical hypothyroidism on C-reactive protein and ischemia modified albumin. Mymensingh Med J 2015;24:379-84.

18. Akinci B, Comlekci A, Yener S, et al. The alteration of serum soluble CD40 ligand levels in overt and subclinical hypothyroidism. Hormones (Athens) 2007;6:327-33.

19. Ozcan O, Cakir E, Yaman H, et al. The effects of thyroxine replacement on the levels of serum asymmetric dimethylarginine (ADMA) and other biochemical cardiovascular risk markers in patients with subclinical hypothyroidism. Clin Endocrinol (Oxf) 2005;63:203-6.

20. Ridker PM, Rifai N, Cook NR, et al. Non-HDL cholesterol, apolipoproteins A-I and B100, standard lipid measures, lipid ratios and CRP as risk factors for cardiovascular disease in women. JAMA 2005;294:326-33.

21. Jae SY, Heffernan KS, Yoon ES, et al. The inverse association between cardiorespiratory fitness and Creactive protein is mediated by autonomic function: a possible role of the cholinergic antiinflammatory pathway. Mol Med 2009;15:291-6.

22. Syamsunder AN, Pal GK, Pal P, et al. Association of sympathovagal imbalance with cardiovascular risks in overt hypothyroidism. N Am J Med Sci 2013;5:554-61.

23. Tian L, Gao C, Liu J, et al. Increased carotid arterial stiffness in subclinical hypothyroidism. Eur J Intern Med 2010;21:560-3.

24. Yu YT, Ho CT, Hsu HS, et al. Subclinical hypothyroidism is associated with elevated high-sensitive C-reactive protein among adult Taiwanese. Endocrine 2013; 44:716-22. 
25. Monzani F, Caraccio N, Kozakowa M, et al. Effect of levothyroxine replacement on lipid profile and intimamedia thickness in subclinical hypothyroidism: a doubleblind, placebo-controlled study. J Clin Endocrinol Metab 2004;89:2099-106.
26. Gullu S, Sav H, Kamel N. Effects of levothyroxine treatment on biochemical and hemostasis parameters in patients with hypothyroidism. Eur J Endocrinol 2005;152:355-61. 